
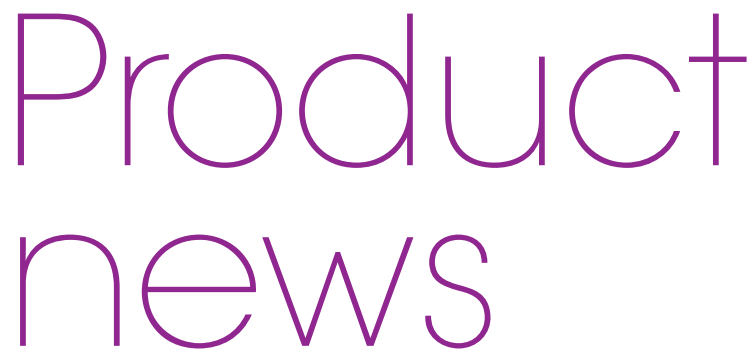

Product news is provided as a service to readers using text and images from

the manufacturer, supplier or distributor and does not imply endorsement

by BDJ Team. Normal and prudent research should be exercised before

purchase or use of any product mentioned.

\section{ACCELERATED HEALING OF TRAUMATISED ORAL TISSUE}

Dent-O-Care are pleased to announce the launch of Gengigel Spray, a new addition to the Gengigel range. Gengigel is a patented formulation containing high molecular weight hyaluronan, a natural physiological constituent produced in the body

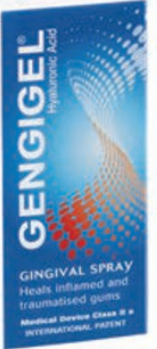
to heal and repair

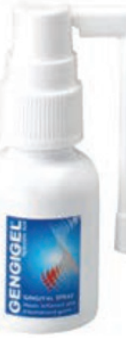
itself. Gengigel is widely endorsed by periodontists and hygienists due to its ability to calm inflammation and promote tissue healing. This exciting product range provides opportunities to better manage traumatised oral conditions such as xerostomia, mouth ulcers, burning mouth syndrome, lichen planus as well as periodontal disease that is resistant to resolution.

Gengigel is the first completely natural topically applied oral care product to help control the host response to manage all sorts of intra-oral inflammatory and painful conditions, as well as patients with periodontal disease that demonstrate poor healing after treatment.

For more information call 02084597550 or email marketing@dentocare.co.uk.

\section{WHITENING TOOTHPASTE WITH CHARCOAL}

Diamond Whites have just launched their Black Edition Paste.

Mixing their best-selling activated charcoal powder with a mint whitening toothpaste, the Black Edition Paste is only $£ 9.99$ and is now available to preorder at www.diamondwhites.co.uk.

Their latest launch follows Diamond Whites' leading Black Edition charcoal range including their Black Edition Charcoal (£13.99) made from $100 \%$ activated coconut shell charcoal. www.diamondwhites.co.uk

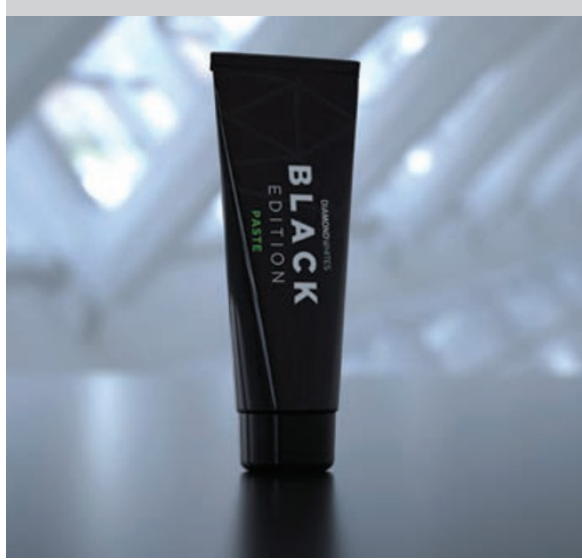

\title{
THE LARGEST DENTAL SHOW IN THE UK IS BACK!
}

As a part of the largest dental show in the UK, Dental Showcase will this year for the first time include a dental surgery of the future on the show floor, featuring a wide range of the latest solutions and products being demonstrated live. The purpose-built practice will include a reception area, patient information zone and the piece-de-resistance-

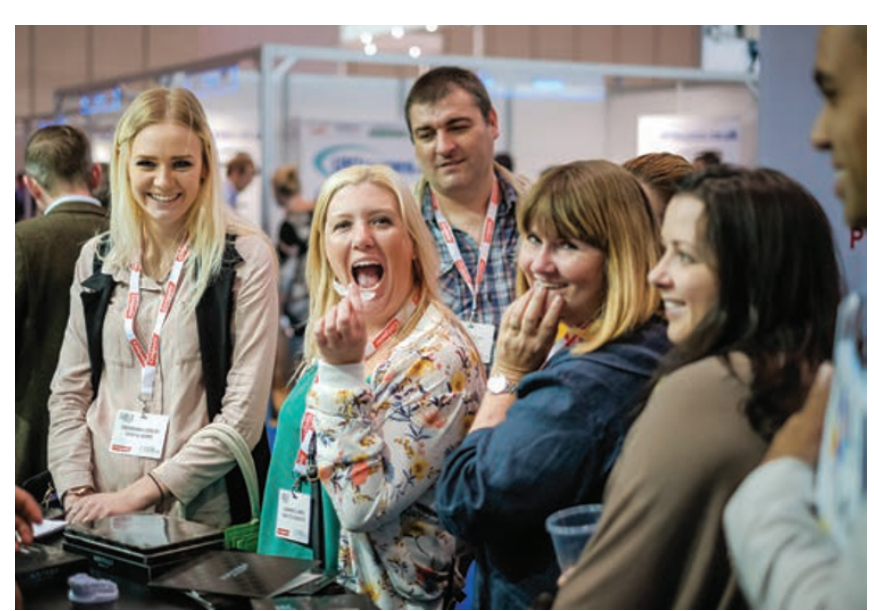

a fully functioning surgery with arena seating for visitors to experience the latest kit within the setting in which it will be used.

Showcase will again host thousands of professionals as they discover the very latest dental innovations across an unrivalled selection of exhibitor stands. Dental team members will enjoy personalised product demonstrations, be able to snap up unbeatable deals and take part in highly engaging lecture sessions whilst toping up their CPD, all under one roof.

While the main thrust of the show will focus on the exhibits, the CPD presentations will include keynotes on the future of dentistry, live demonstrations on how to handle medical emergencies, ergonomics, innovations in $\mathrm{X}$-rays, 3D printing, how to make the right purchasing decisions, IRMER and much more. Sessions will be a combination of live demonstrations, interactive lectures, walkarounds and panel discussions.

In addition to all the other traditional benefits of attending Showcase there will be a new feature located on the show floor which will provide a platform for GDPs to learn from key opinion leaders in implantology, endodontics and orthodontics. The 30-minute seminar sessions will be followed by networking with specialists from each region of the UK.

Witness the future in the present - Dental Showcase 2017 is a must for everyone who needs to be in the know. To register your place at the event, which will take place at Birmingham NEC from 19-21 October 2017, log onto http://www.dentalshowcase. com/register. 


\section{EXCITING COLOUR REFRESH FOR INTERDENTAL BRUSHES}

TePe's interdental brushes have received an exciting colour refresh. The refreshed colours will remain consistent to their current sizing, and same high quality, but benefit from a modern new look.

Alongside the colour refresh, TePe's interdental brushes have also received two further updates. The patented soft neck, on the four smallest sizes, is now highlighted with a semi-transparent colour to further emphasise its highly flexible nature and a new look has been created for the cap, which functions as both a hygienic brush protector and smart handle extension.

TePe has been recommended by the dental profession in the UK for over 15 years. TePe offers a wide range of interdental brushes in nine different sizes to fit a variety of gaps, and are endorsed and recommended by $94 \%$ of dental hygienists in the UK. ${ }^{1}$

1. Eaton K A, Harris M, Ross M K, Arevalo C. A survey of dental hygienists in the United Kingdom in 2011. Part 1

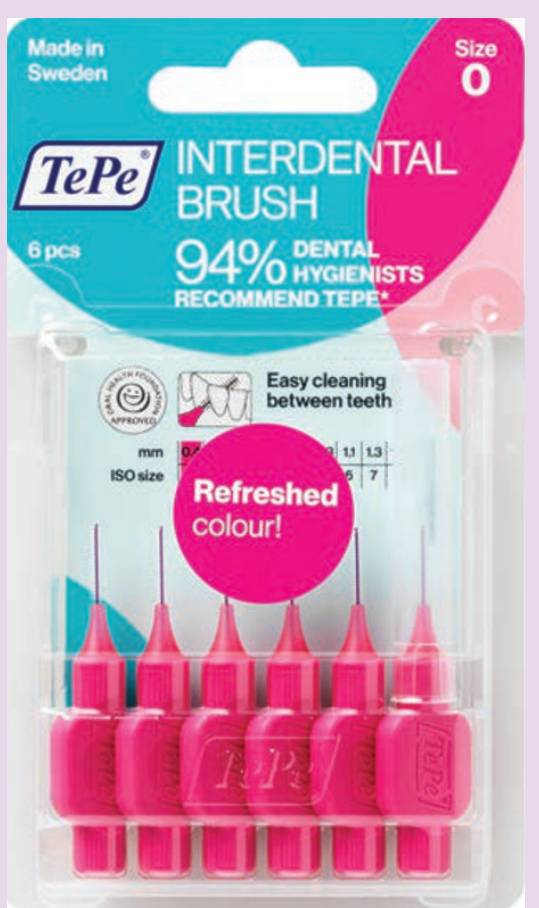

- demographics and working patterns as dental hygienists. Br Dent $J$ 2012; 213: E18.

\section{A BRUSH THAT BRIGHTENS YOUR SMILE AND YOUR BATHROOM}

FOREO have launched the ISSA play, a toothbrush that brightens your smile and brings style to your bathroom. The ISSA play is the perfect introduction to FOREO's oral care line in a batterypowered model. Combining Sonic Pulse Technology with a unique hybrid brush head, the ISSA play is strong on plaque and gentle on gums.

FOREO is the first company to apply the unique properties of silicone to both facial-cleansing and oral-care devices. Every device uses smooth silicone that is body-safe and hypoallergenic, offering safe, gentle and effective solutions. FOREO products are free of phthalates and BPA and silicone is easy to clean and quick-drying, while its nonporous surface prevents bacteria buildup, as well as the absorption of toothpaste and gels, unlike fully nylon bristled brushes.

The ISSA play's silky soft bristles massage the gums and do not scratch tooth enamel. Up to 9,000 high intensity pulsations a minute create micro-sweeps that break up and remove plaque for effective cleaning while also massaging gums to feel healthier and stronger.

The smart, Swedish designed ISSA play comes in a vibrant range of colours, is ergonomic, lightweight and travelfriendly. It is also $100 \%$ waterproof and cost effective, with no changeable brush heads. The ISSA play require two AAA batteries and can be used for up to six months.

The ISSA play is available to purchase for $£ 39$ from https://www.foreo.com/issa-play.

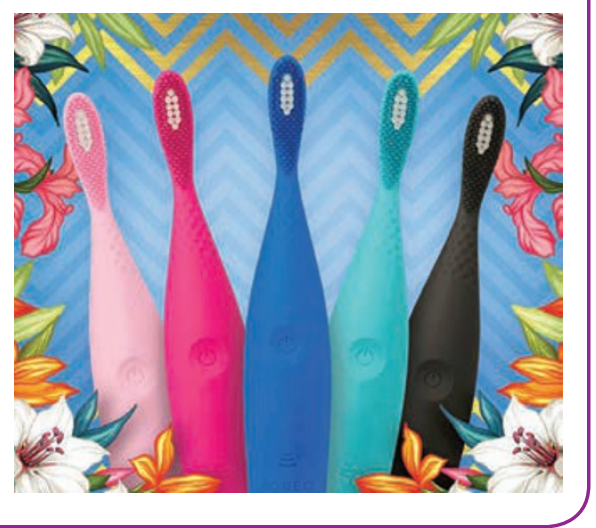

APPLE AND MILD MINT TOOTHPASTE FOR KIDS

Buddies is an innovative range of oral care products designed for children aged from two years. The toothpaste formula comes in gentle flavours that have been developed with young taste buds in mind: Hint of Mint has a mild butter mint flavour and Apple Fresh is a zingy f flavour for children who aren't keen on mint.

Buddies also offer a rechargeable toothbrush for children aged from three which come in two eye-catching designs featuring the Buddies characters,

Hint of Mint and Apple Fresh. When

l loaded with a toothpaste cartridge,

pushing down on the collar of the brush automatically dispenses just the right amount of toothpaste onto the bristles. What's more, the charging base not only charges the electric toothbrush but also lights up with a comforting glow as a night-light for your children's bedroom.

The Buddies toothbrush head gently vibrates for two minutes, getting children used to the sensation of electric toothbrushes.

Buddies toothpaste contains 1450 ppm fluoride, which is within the recommended amount for children aged three plus using the pea-sized amount as dispensed by the Buddies toothbrush. Children under three should use a smear of Buddies toothpaste.

CTS Dental Supplies are the exclusive UK distributor of the Buddies range of oral care products.

To place an order, call 01737765400 or visit www. buddiestoothpaste. com. dental industry in BDJ Team, call Andy May on 02078434785 or emaila.may@nature.com. 